Results: Two hundred forty-two SLE patients were evaluated; $94.4 \%$ of them were female. Mean values were as follow: age at diagnosis $33.29 \pm 13.53$ years, disease duration $15.82 \pm 10.56$ years, SLEDAI $5.91 \pm 5.06$, SLICC score $1.06 \pm 1.42$, BLyS levels $1.811 \pm 1.757 \mathrm{ng} / \mathrm{mL}$. The $22.5 \%$ of patients displayed increased BLyS levels. The $29.6 \%$ of total patients exhibit SLEDAI values up to 6 , and only the $7 \%$ of them showed SLEDAl values up to 6 and high BLyS levels simultaneously. Higher BLyS levels were significantly correlated to the ANAs positivity $(p=0.0006)$ and lymphopenia $(p=0.01)$ but showed no correlation with hypocomplementemia neither anti-dsDNA. The statistical analysis did not yield differences in the clinical activity or accumulated damage between patients with lower and higher BLyS levels.

Conclusions: In our series we observed a $22.5 \%$ of patients with high levels of BLyS, and the 7\% of cases had BLyS high levels and SLEDAl>6. BLyS upregulation is related to ANAs positivity and lymphopenia. We have found no statistical evidences on the relationship of BLyS levels and clinical activity in our series of patients.

Disclosure of Interest: None declared

DOI: 10.1136/annrheumdis-2017-eular.4186

\section{AB0494 INCREASED LEVELS OF INTERFERON ALPHA AND INTERLEUKIN-10 AS CLINICAL ACTIVITY BIOMARKERS IN SYSTEMIC LUPUS ERYTHEMATOUS PATIENTS}

E. Grau Garcia ${ }^{1}$, M. Fernandez Matilla ${ }^{2}$, C.M. Feced Olmos ${ }^{1}$, E. Labrador Sánchez ${ }^{1}$, F.M. Ortiz-Sanjuan ${ }^{1}$, N. Fernández-Llanio ${ }^{2}$, E. Tovar Sugreñes ${ }^{3}$ K. Arévalo Ruales ${ }^{1}$, R. Negueroles Albuixech ${ }^{1}$, J. Ivorra Cortes ${ }^{1}$, J.J. Fragio Gil $^{1}$, I. Martínez Cordellat ${ }^{1}$, R. González Mazarío ${ }^{1}$, I. Chalmeta Verdejo ${ }^{1}$ L. Gonzalez Puig ${ }^{1}$, C. Alcañiz Escandell ${ }^{1}$, C. Nájera Herranz ${ }^{1}$, I. Cánovas Olmos $^{1}$, E. Vicens Bernabeu ${ }^{1}$, J.E. Oller Rodriguez ${ }^{1}$, J.A. Castellano Cuesta ${ }^{2}$, V. Fornés Ferrer ${ }^{4}$, D. Hervás Marín ${ }^{4}$, J.A. Román Ivorra ${ }^{1,3}{ }^{1}{ }^{1}$ Rheumatology Department, HUP la Fe, ${ }^{2}$ Rheumatology Section, Hospital Arnau de Vilanova; ${ }^{3}$ Medical School, UCV; ${ }^{4}$ Biostatistics Unit, IIS la Fe, Valencia, Spain

Background: Systemic lupus erythematous (SLE) is an autoimmune disease characterized by immune system disruption, including deregulation of cytokine production. Interferon alpha (INF1A) is considered a key molecule in SLE etiopathogenesis, being responsible of the differentiation of dendritic cells from monocytes, and indirectly of interleukin 10 (IL10) upregulation. The B lymphocyte stimulating factor (BLyS) is involved in autoantibodies production and clinical activity, and is regulated by other cytokines as IL10 and INF1A.

Objectives: To analyze the association among INF1A, IL10 and BLyS levels and clinical activity in SLE.

Methods: A cross-sectional, observational study of 142 patients diagnosed of SLE according to SLICC 2012 criteria and 34 healthy controls was performed. A complete blood-test was made, and clinical data by personal interview was collected. We analyzed serum concentration of IL10, BLyS and INF1A by colorimetric methods. Patients were dichotomized as high and low levels for each cytokine based on the cytokine level above $2 \mathrm{SD}$ of the mean in healthy controls. Biostatistical analysis with $\mathrm{R}$ (3.3.2.) was performed.

Results: In our SLE patients we observed higher values of IL10, BLyS and INF1A than controls $(P<0.001, P=0.005$ and $P=0.043$ respectively), showing an average values in patients of $13.39 \pm 27.73 \mathrm{pg} / \mathrm{mL}$ INF1A, $9.99 \pm 15.84 \mathrm{pg} / \mathrm{mL}$ IL10 and $1811.31 \pm 1757.81 \mathrm{pg} / \mathrm{mL}$ BLyS. The mean clinical activity measured by SLEDAI was $5.91 \pm 5.06$.

Statistical analysis indicate that INF1A levels are correlated to IL10 levels $(P=0.001)$ and BLyS levels $(P=0,034)$. Due to this finding, we categorized SLE patients by low or high level of the three cytokines: 44 INF1A(-)IL10(-)BLyS(-); 61 INF1A(+)IL10(-)BLyS(-); 5 INF1A(+)IL10(-)BLyS(+); 18 INF1A(+)IL10(+)BLyS(-) and $14 \operatorname{INF} 1 \mathrm{~A}(+) \operatorname{IL} 10(+) \mathrm{BLyS}(+)$. There is a high association of increased IL10INF1A levels and the increased of clinical activity by SLEDAI score $(P<0.001)$, and to a lesser extent with increased IL10-INF1A-BLyS levels. Patients with high IL10-INF1A and IL10-INF1A-BLyS showed a significant rise in C3-C4 consumption $(P<0.001$ and $P=0.001$ respectively) and high anti-dsDNA $(P=0.001$ and $P=0.002$ respectively). Patients with increased INF1A-BLyS exhibited high anti-dsDNA $(P=0.004)$ and ENA positivity $(P<0.001)$. In addition, patients with increased levels of IL10-INF1A-BLyS showed ANAs $(P<0.001)$ and antiphospholipid autoantibody positivity $(\mathrm{P}=0.004)$

Conclusions: The $69 \%$ of our SLE patients displayed almost one cytokine increased, being the INF1A the cytokine that mainly is increased. However, increased IL10 levels, irrespective of whether there is also increased levels of BLyS and/or INF1A, is the cytokine which best fits to clinical activity in SLE.

Disclosure of Interest: None declared

DOI: 10.1136/annrheumdis-2017-eular.4180

\section{AB0495 ASSESSMENT OF FRACTURE RISK IN A COHORT OF EGYPTIAN FEMALE SYSTEMIC LUPUS ERYTHEMATOSUS PATIENTS}

E.A. Hafez ${ }^{1}$, S.A. El Bakry ${ }^{1}$, S.I. Ibrahim ${ }^{1}$, C.S. Morad ${ }^{1,1}$, S.A. Hamza ${ }^{2}$, D.M. Abd El-Khalik ${ }^{1} .{ }^{1}$ Internal medicine and Rheumatology; ${ }^{2}$ Geriatric Medicine, Faculty of Medicine, Ain Shams University, Cairo, Egypt

Background: Survival of systemic lupus erythematosus (SLE) patients has improved dramatically due to improved treatment, and the morbidity pattern has shifted towards long-term complications as osteoporosis. SLE occurs in women during child-bearing years and the disease often persists to the postmenopausal period ${ }^{1}$. Assessment of fracture risk in SLE patients is important as fractures may occur while bone mineral density (BMD) is above the osteoporotic threshold or at the normal range ${ }^{2}$. Osteocalcin measurement helps to assess fracture risk and select patients for treatment.

Objectives: To assess the fracture risk in a cohort of Egyptian female SLE patients by using BMD and osteocalcin level with correlation to disease activity, damage index and drugs in use.

Methods: 70 females with SLE $\geq 40$ years old satisfying the SLICC classification criteria were enrolled with detailed history taking including disease duration, drugs in use, traditional risk factors, regular exercise, history of previous fractures and menstrual history. Assessment of disease activity using Systemic Lupus Erythematosus Disease Activity Index (SLEDAI) and disease damage using the Systemic Lupus International Collaborative Clinics/ American College of Rheumatology Damage Index (SLICC/ACR DI). Serum calcium, phosphorus and alkaline phosphatise were measured. BMD measured by dual energy X-ray absorpiometry (DEXA) scans at lumbar spine (LS) (L2-L4) and femoral neck (FN), serum osteocalcin level and World Health Organization fracture risk assessment tool $\left(\right.$ FRAX $\left.{ }^{\circledR}\right)$

Results: 14//70 (20\%) patients had LS osteoporosis, 25//70 (35.7\%) had LS osteopenia and 6/70 (8.6\%) had FN osteoporosis, 30/70 (42.9\%) had FN osteopenia. FRAX-Major $\geq 20 \%$ was observed in $10 \%$ of patients, FRAX-HIP $\geq 3 \%$ was seen in $27.1 \%$ of patients. Serum osteocalcin level was significantly decreased in SLE patients with lower BMD than those with normal BMD, and significantly decreased in patients with osteoporosis than those with osteopenia. A significant negative correlation was found between osteocalcin level and age of patients, disease duration, SLEDAI and SLICC scores, current, IV pulse and cumulative steroids, immunosuppressants, anticoagulants, but there was a positive correlation with antimalarials and calcium supplements.

Conclusions: SLE patients are at greater risk for developing osteoporosis and osteopenia. Ten-year risk of major and hip fractures was high in SLE patients. Increasing age, disease duration, high anti-DNA titres, SLEDAI and SLICC were associated with a higher 10-year probability of major osteoporotic fracture. FRAX predicted incident hip and major osteoporotic fractures among SLE patients with normal and low bone mass not just those with frank osteoporosis. Physicians should be alerted to the higher risk of future fractures in SLE patients for periodic monitoring.

\section{References:}

[1] Furukawa M, Kiyohara C, Horiuchi T, Tsukamoto H, Mitoma H, Kimoto Y et al. Prevalence and risk factors of vertebral fracture in female Japanese patients with systemic lupus erythematosus. Mod Rheumatol, 2013; 4:765-73.

[2] Van den Bergh J, Van Geel T, Lems W and Geusens P. Assessment of individual fracture risk: FRAX and beyond. Curr Osteoporos Rep, 2010; 8:131-7.

Disclosure of Interest: None declared

DOI: 10.1136/annrheumdis-2017-eular.3907

\section{AB0496 VENOUS THROMBOSIS IS MORE PREVALENT IN PATIENTS WITH ANTIPHOSPHOLIPID SYNDROME (APS) ACCOMPANYING SYSTEMIC LUPUS ERYTHEMATOSUS, WHILE LIVEDO RETICULARIS IN PRIMARY APS}

E.N. Haładyj, A. Wieczorek, M. Olesińska. Connective Tissue Diseases, Institute of Geriatrics, Rheumatology and Rehabilitation, WARSAW, POLAND, Warsaw, Poland

\section{Background:}

APS more often overlaps with other systemic autoimmune diseases like systemic lupus erythematosus (SLE) or rheumatoid arthritis (RA) than occur as a distinct disease. Our purpose was to evaluate what are the differences between patients with primary APS and APS accompanying SLE.

Objectives: The objective of this study was to compare patients with primary APS and APS/SLE group whther we can find find any clinical or laboratory parameters that can distinguish them from each other.

Methods: 112 patients with APS were included to the study, 57 of them with primary APS and 55 with coexisting SLE. These patients were followed at the Department of Connective Tissue Diseases, NIGRiR, Warsaw, Poland. At inclusion a full medical history and physical examination data were recorded.

Results: Both groups were similar in age, gender and duration of disease. Among all the clinical manifestations of APS, venous thrombosis was more frequent in patients with concomitant SLE. Skin involvement was significantly more prevalent in primary APS and it was caused mainly by livedo reticularis presence. From neurological manifestations, the occurrence of epilepsy was comparable, when EEG changes were more frequent in APS/SLE group. From laboratory measures, leucopenia, low complement concentrations and proteinuria were more prevalent in APS/SLE group. No differences were observed in thrombocytopenia and elongation of APTT as well as antiphospholipid antibody profile.

Conclusions: In conclusion, arterial thrombosis is more characteristic for primary APS. We found that livedo reticularis is very characteristic feature for primary APS. Although epilepsy occurrence is comparable in APS and APS/SLE, higher frequency of EEG changes in APS/SLE group suggests that the mechanisms 